\title{
Modeling study on the transport of summer dust and anthropogenic aerosols over the Tibetan Plateau
}

\author{
Y. Liu ${ }^{1, *}$, Y. Sato ${ }^{2, *}$, R. Jia ${ }^{1}$, Y. Xie ${ }^{1}$, J. Huang ${ }^{1}$, and T. Nakajima ${ }^{3}$ \\ ${ }^{1}$ Key Laboratory for Semi-Arid Climate Change of the Ministry of Education, College of Atmospheric Sciences, \\ Lanzhou University, Lanzhou, 730000, China \\ ${ }^{2}$ Advanced Institute for Computational Science, RIKEN, Kobe, Hyogo, 6500047, Japan \\ ${ }^{3}$ Earth Observation Research Center, JAXA, Tsukuba, Ibaraki, 3058505, Japan \\ *These authors contributed equally to this work.
}

Correspondence to: Y. Liu (liuyzh@1zu.edu.cn)

Received: 22 April 2015 - Published in Atmos. Chem. Phys. Discuss.: 29 May 2015

Revised: 23 September 2015 - Accepted: 12 October 2015 - Published: 11 November 2015

\begin{abstract}
The Tibetan Plateau (TP) is located at the juncture of several important natural and anthropogenic aerosol sources. Satellites have observed substantial dust and anthropogenic aerosols in the atmosphere during summer over the TP. These aerosols have distinct effects on the earth's energy balance, microphysical cloud properties, and precipitation rates. To investigate the transport of summer dust and anthropogenic aerosols over the TP, we combined the Spectral Radiation-Transport Model for Aerosol Species (SPRINTARS) with a non-hydrostatic regional model (NHM). The model simulation shows heavily loaded dust aerosols over the northern slope and anthropogenic aerosols over the southern slope and the east of the TP. The dust aerosols are primarily mobilized around the Taklimakan Desert, where a portion of the aerosols are transported eastward due to the northwesterly current; simultaneously, a portion of the particles are transported southward when a second northwesterly current becomes northeasterly because of the topographic blocking of the northern slope of the TP. Because of the strong upward current, dust plumes can extend upward to approximately $7-8 \mathrm{~km}$ a.s.l. over the northern slope of the TP. When a dust event occurs, anthropogenic aerosols that entrained into the southwesterly current via the Indian summer monsoon are transported from India to the southern slope of the TP. Simultaneously, a large amount of anthropogenic aerosol is also transported from eastern China to the east of the TP by easterly winds. An investigation on the transport of dust and anthropogenic aerosols over the plateau may provide the
\end{abstract}

basis for determining aerosol impacts on summer monsoons and climate systems.

\section{Introduction}

Aerosols, which primarily comprise a mixture of soil dust, sulfate, carbonaceous material and sea salt, may have a large, direct effect on the energy balance by absorbing and scattering solar and thermal radiation (Liu et al., 2011, 2014; Miller and Tegen, 1998; Tegen, 2003) and an indirect effect on the microphysical properties of clouds (DeMott et al., 2003; Huang et al., 2010). Mineral dust, which is the main component of aerosols, is a primary type of absorbing aerosol (Huang et al., 2007a, 2011; Sokolik and Toon, 1996). Asia dust (Hsu et al., 2013; Nakajima et al., 2003) and anthropogenic aerosols create a significant environmental problem when mixed during transport (Takemura et al., 2002). Asia dust, which generally originates from Outer and Inner Mongolia, the Taklimakan Desert, and the Gobi Desert, and anthropogenic aerosols can be transported eastward by the jet stream to North America across the North Pacific Ocean (Gong et al., 2006; Takemura et al., 2002; Uno et al., 2001).

Atmospheric aerosols are dispersed worldwide (Breider et al., 2014; Goudie and Middleton, 2001; Müller et al., 2003). Recent studies indicate that dust aerosols accumulate over the northern slope of the Tibetan Plateau (TP) (Chen et al., 2013; Huang et al., 2007b). As the highest plateau in the world, the TP may influence the climate through dynami- 
cal and thermal forcing (Wu et al., 2007) and by modulating the hydrologic cycle (Hansen et al., 2000; Jacobson, 2001). The TP is located at the juncture of several important natural and anthropogenic aerosol sources and is surrounded by the earth's highest mountains, e.g., the Himalayas and the Pamir and Kunlun Mountain ranges; the Taklimakan Desert lies to the north, the Gobi Desert lies to the northeast and the Great Indian Desert lies to the southwest. With an increasing frequency of nearby dust storms (Thulasiraman et al., 2002; Uno et al., 2001), the TP faces new threats from aerosols.

As the major type of aerosol that affects the TP (Huang et al., 2007b; Zhang et al., 2001), dust aerosols accumulate on the northern slope of the plateau, where the Taklimakan and Gobi deserts intersect. From April to May, dust aerosols, which are transported from Pakistan/Afghanistan, the Middle East, the Sahara, and Taklimakan deserts, accumulate at high elevations on the southern and northern slopes of the TP (Lau et al., 2006). The largest number of dust storms occurred over the northern slope and eastern part of the TP in the spring of 2007, and several dust layers were elevated to altitudes of 11-12 km (Liu et al., 2008). During summer, dust aerosol particles are transported from nearby deserts, such as the Taklimakan Desert, and accumulate on the northern and southern slopes of the TP. Tibetan dust aerosol layers appear most frequently at approximately $4-7 \mathrm{~km}$ above the mean sea level, where the plumes likely originate from the nearby Taklimakan Desert and accumulate over the northern slopes of the TP during summer (Huang et al., 2007b). As the dust storm travels toward the TP, the dust aerosols may mix with anthropogenic aerosols (Takemura et al., 2002) and induce new environmental and climatic problems (Jing Su et al., 2008).

The elevated absorbing aerosols have a unique feedback with the high surface albedo of the TP (Liu et al., 2013). According to a modeling study, the atmosphere in the upper troposphere over the TP may act as an "elevated heat pump" (Lau and Kim, 2006), which can be affected by the absorption of solar radiation by dust coupled with black carbon emitted from industrial areas in northern India; this setup may advance and subsequently intensify the Indian monsoon. However, the Tibetan aerosol distribution and properties are largely unknown.

In this study, we firstly evaluated the Spectral RadiationTransport Model for Aerosol Species (SPRINTARS) combined with a non-hydrostatic regional model (NHM) through comparing the simulation results and satellite observations, including the altitude-orbit cross section of the extinction coefficient along the trajectory of Cloud-Aerosol Lidar and Infrared Pathfinder Satellite Observations (CALIPSO), the aerosol index (AI) in the ultraviolet (UV) band from an ozone monitoring instrument (OMI), and monthly mean aerosol optical depth (AOD) data from a multi-angle imaging spectroradiometer (MISR). Simultaneously, the dust and anthropogenic aerosols in summer over the TP are evaluated, and their distributions over the TP are presented. The transport of these aerosols is also explored via combining the simulation results and reanalysis data.

\section{Model description}

\subsection{Adding SPRINTARS to the NHM}

The three-dimensional aerosol transport-radiation model called SPRINTARS (Takemura et al., 2000, 2002) is used in this study. This global aerosol climate model was developed at the Center for Climate System Research (CCSR), University of Tokyo. The model simultaneously considers the main tropospheric aerosols, i.e., carbon (organic carbon (OC) and black carbon (BC)), sulfate, soil dust, and sea salt, and the precursor gases of sulfate, i.e., sulfur dioxide $\left(\mathrm{SO}_{2}\right)$ and dimethyl sulfide (DMS). The aerosol transport processes include emission, advection, diffusion, sulfur chemistry, wet deposition, dry deposition, and gravitational settling.

Although SPRINTARS was originally based on a general circulation model (GCM), i.e., CCSR/NIES/FRCGC AGCM (Numaguti et al., 1997) called the Model for Interdisciplinary Research on Climate (MIROC), to investigate the regional distribution and transport of dust and anthropogenic aerosols over the TP, we combined SPRINTARS with a regionalscale NHM developed by the Japan Meteorological Agency (JMANHM) (Saito et al., 2006). The dynamical field of the JMA-NHM drives the transport of aerosols included in SPRINTARS (hereafter referred to as NHM-SPRINTARS or simply SPRINTARS).

The Arakawa-C and Lorentz grid structures were adopted for the horizontal and vertical grid configurations, respectively. Originally, the advection scheme for tracers (i.e., mixing ratio of hydrometeors, aerosols and gases) in NHM did not guarantee mass conservation. In adding SPRINTARS to NHM in this study, the advection scheme of Walcek and Aleksic (1998), which guarantees mass conservation, was applied in the transport of aerosols and chemical tracers. Using the advection scheme, Kajino et al. (2012) successfully simulated the transport of a chemical tracer. The turbulence scheme of Nakanishi and Niino (2006) and the two-moment bulk cloud microphysical scheme of Yamada (2003) were used.

\subsection{Experiment setup}

A simulation of the coupled NHM and SPRINTARS was conducted. The model domain covered $15.72-53.33^{\circ} \mathrm{N}$ and $60.58-119.09^{\circ} \mathrm{E}$, as shown in Fig. 1. A horizontal resolution of $20 \mathrm{~km} \times 20 \mathrm{~km}$ was used. Vertically, 40 levels with variable intervals from 40 to $1120 \mathrm{~m}$ were used. The experiment was conducted for August of 2007 at a time step of $\Delta t=5.0 \mathrm{~s}$.

The $6 \mathrm{~h}$ data set of Japanese 25-year Reanalysis (JRA-25) (Onogi et al., 2007) was used for the initial and lateral boundaries of the horizontal wind field, temperature, and specific 


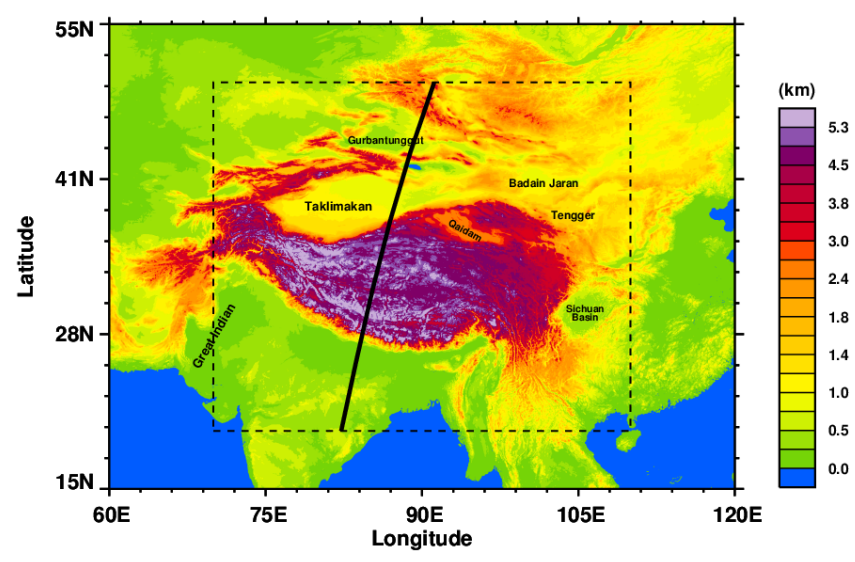

Figure 1. Modeling domains and topography over the vicinity of the TP; the contours of the terrain height are in $\mathrm{km}$ (above mean sea level). The solid black line indicates the trajectory of the CALIPSO satellite over the TP on 22 August 2007. The black rectangle indicates the survey region.

humidity during the simulated period. The vertical wind field of the initial and boundary conditions was set to 0 .

The initial and boundary conditions of the aerosol fields were created through downscaling the results of SPRINTARS in a general circulation model, MIROC-SPRINTARS (Takemura et al., 2005; Goto et al., 2011). Every $6 \mathrm{~h}$ result from MIROC-SPRINTARS, for which the horizontal and vertical resolutions were $1.1^{\circ} \times 1.1^{\circ}$ and 20 layers, respectively, was interpolated to determine the initial and lateral boundary conditions of the aerosol and precursor gases (DMS and $\mathrm{SO}_{2}$ ) (details on the experiment setup of MIROCSPRINTARS are described in the Appendix).

The emission inventory data of anthropogenic black carbon and $\mathrm{SO}_{2}$ are based on Lamarque et al. (2010), and the other inventories (i.e., biomass burning and volcanoes) are the same as those used by Takemura et al. (2005). In addition to the aerosol field and emission data, the three-dimensional oxidant distribution is required to calculate the chemical reaction of sulfate aerosols in each grid. The monthly mean oxidant distributions were prescribed from the chemical transport model CHASER coupled with MIROC (MIROCCHASER) (Sudo et al., 2002), with a horizontal resolution of $2.8^{\circ} \times 2.8^{\circ}$.

The original pre-calculated parameters of simulated aerosols used in this study, refractive indices at $0.55 \mu \mathrm{m}$ and effective radius, are listed in Table 1. In this model, the particle sizes of dust, BC, OC, sea salt and sulfate aerosols are divided into 10, 9, 9, 4 and 8 radii, respectively, for different radius ranges as given in Table 1 . And the refractive index of each aerosol component is uniform for all the radius subranges based on d'Almeida et al. (1991) and the imaginary part of soil dust aerosols is updated for their weaker absorption of the solar radiation (Kaufman et al., 2001).

\section{Observational data}

\subsection{CALIPSO profiles}

Combining an active Lidar instrument, i.e., the CloudAerosol Lidar with Orthogonal Polarization (CALIOP), with passive infrared and visible imagers, the CALIPSO satellite provides new insight into the vertical structure and properties of clouds and aerosols. In this study, the CALIPSO Level 1B and Level 2APro data sets (aerosol profile), which contain a half-orbit (day or night) of calibrated and geolocated singleshot (highest resolution) Lidar profiles, were used to detect dust events and evaluate the model.

The CALIPSO Level 1B product provides the profiles of the total attenuated backscatter at 532 and $1064 \mathrm{~nm}$ and a volume depolarization ratio at $532 \mathrm{~nm}$; the optical depth of aerosols from CALIPSO Level 2APro was used to increase the reliability of the dust detection. The Level 2APro product also provides the extinction coefficient profiles at $532 \mathrm{~nm}$, which were used to evaluate the SPRINTARS model in the vertical direction. Because aerosols and clouds generally have a larger spatial variability and stronger backscatter intensity at lower altitudes, the investigation focuses on altitudes ranging from 0 to $10 \mathrm{~km}$ a.s.l. to obtain a higher accuracy.

\subsection{OMI AI}

The ozone monitoring instrument (OMI) aboard the Earth Observation System (EOS) Aura spacecraft provides daily global coverage of the Earth-atmosphere system at wavelengths ranging from 270 to $500 \mathrm{~nm}$ with a high spatial resolution of $13 \mathrm{~km} \times 24 \mathrm{~km}$ and a swath width of approximately $2600 \mathrm{~km}$. The OMI Aerosol (OMAERO) Level 2 product contains the characteristics of absorbing aerosols in the full instrument resolution. The OMI AI in the UV band was compared with the aerosol optical depth (AOD) simulated by SPRINTARS.

\subsection{MISR AOD}

The MISR, which was launched with the sun-synchronous polar-orbiting Terra, can simultaneously view the sunlit Earth at the same point in nine widely spaced angles ranging from $70^{\circ}$ afterward to $70^{\circ}$ forward of the local vertical at a spatial sampling resolution of 275 to $1100 \mathrm{~m}$ globally. The MISR can even retrieve aerosol properties over highly reflective surfaces, such as deserts, and it has few limitations caused by the surface type (Christopher et al., 2008; Kahn et al., 2005; Martonchik, 2004). The MISR Level 3 AOD product, which is retrieved from multiple orbits at a monthly timescale on geographic grids of $0.5^{\circ} \times 0.5^{\circ}$, was used to evaluate the simulated monthly mean properties of all of the aerosols in this study. 
Table 1. Refractive indices ( $\left.R_{\text {eff }}\right)$ at 0.55 and effective radius of each size bin for different aerosol component in SPRINTARS.

\begin{tabular}{lll}
\hline Component & $R_{\text {eff }}(\mu \mathrm{m})$ & Refractive index \\
\hline Dust & 0.130 .200 .330 .520 .821 .272 .023 .205 .068 .02 & $1.530-2.00 \times 10^{-3} i$ \\
BC & 0.1000 .1080 .1100 .1440 .1690 .1960 .2740 .312 & $1.750-0.440 i$ \\
OC & 0.1000 .1080 .1100 .1440 .1690 .1960 .2740 .312 & $1.377-3.60 \times 10^{-3} i$ \\
Sea salt & 0.1780 .5621 .785 .62 & $1.381-4.26 \times 10^{-9} i$ \\
Sulfate & 0.06950 .0850 .0950 .1030 .1220 .1570 .1950 .231 & $1.430-1.00 \times 10^{-8} i$ \\
\hline
\end{tabular}

\subsection{ERA-Interim reanalysis data}

The European Centre for Medium-Range Weather Forecasts (ECMWF) ERA-Interim reanalysis data set was used to evaluate the meteorological fields of SPRINTARS and analyze the transport of the aerosols. Daily meteorological contours of the $U$ and $V$ components of the wind speed and the vertical velocity from ECMWF were used. The reanalysis data have a spatial resolution of $1.0^{\circ} \times 1.0^{\circ}, 37$ pressure levels in the vertical direction, and a temporal resolution of $6 \mathrm{~h}(00: 00$, 06:00, 12:00 and 18:00 UTC).

\section{Results and discussion}

Considering the influence of the lateral boundary of the model domain, the analysis primarily focused on the inner domain of $20-50^{\circ} \mathrm{N}, 70-110^{\circ} \mathrm{E}$, as indicated by the black rectangle in Fig. 1; this area encloses the TP and most of the dust sources in East Asia.

The TP is located in central East Asia $\left(25-40^{\circ} \mathrm{N}, 74-\right.$ $104^{\circ} \mathrm{E}$ ), where the average elevation is $4500 \mathrm{~m}$. For the northeast TP, the Taklimakan, Gurbantunggut, and Badain Jaran deserts are the primary dust sources outside the local desert in the Qaidam Basin. For the west TP, the Taklimakan Desert, Great Indian Desert and deserts in Central Asia are the primary dust sources. Although the area southeast of the TP is far from the dust sources, anthropogenic aerosols could be transported from India and east of China. The aerosols over the TP may consist of particles transported from these sources and anthropogenic aerosols, including carbonaceous and sulfate aerosols from India and east of China. The solid black line in Fig. 1 indicates the trajectory of the CALIPSO satellite over the TP on 22 August 2007.

\subsection{Identification of a dust event}

The product of CALIPSO, which can observe aerosols over bright surfaces and beneath thin clouds in clear skies (Vaughan et al., 2004; Winker et al., 2006), was used to identify dust aerosols. With a total attenuated backscatter coefficient at $532 \mathrm{~nm}$, the depolarization ratio and AOD from CALIPSO were combined to identify dust aerosols. Generally, because of its non-sphericity, dust has a larger depolarization ratio than raindrops and other aerosols and has

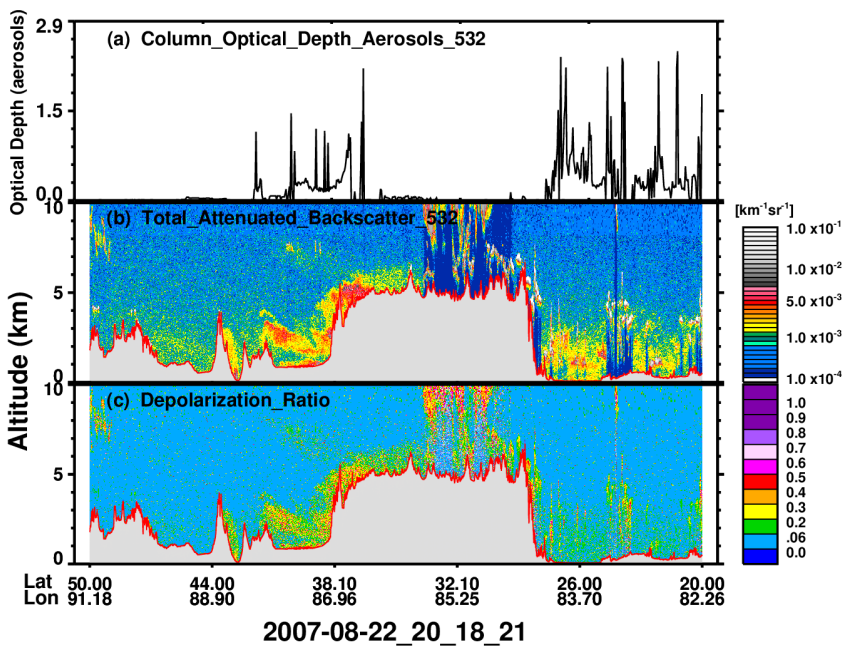

Figure 2. Aerosol optical depth (a), altitude-orbit cross-sections of the total attenuated backscattering (b) and depolarization ratio (c) on 22 August 2007 along the trajectory of the CALIPSO satellite over the TP, as presented in Fig. 1. The gray shading indicates the topography.

a smaller depolarization ratio than an ice cloud. To identify dust aerosols, values of $0.0008-0.048 \mathrm{~km}^{-1} \mathrm{sr}^{-1}$ and 0.06-0.4 were chosen as the thresholds of the total attenuated backscatter and volume depolarization ratio, respectively (Chen et al., 2009; Li et al., 2013; Liu et al., 2008; Shen et al., 2010; Zhao et al., 2009).

The CALIPSO data analysis shows (figures omitted) that a large amount of aerosol is present over the TP during summer. A typical case on 22 August 2007 was investigated in detail. Figure 2 shows the (a) AOD, the altitude-orbit cross-section of the (b) total attenuated backscattering intensity and (c) depolarization ratio on 22 August 2007 along the CALIPSO trajectory presented in Fig. 1 . The gray shading in Fig. 2 indicates the topography, and the deep blue area denotes the absence of signal due to clouds, which the laser cannot penetrate. As shown in Fig. 2, the total attenuated backscatter and volume depolarization ratio ranged from 0.002 to $0.005 \mathrm{~km}^{-1} \mathrm{sr}^{-1}$ and 0.06 to 0.3 , respectively. Based on the thresholds for identifying dust aerosols, 22 August 2007 is considered a severe dusty day. Thick dust plumes existed over both the southern and northern slopes of the TP 

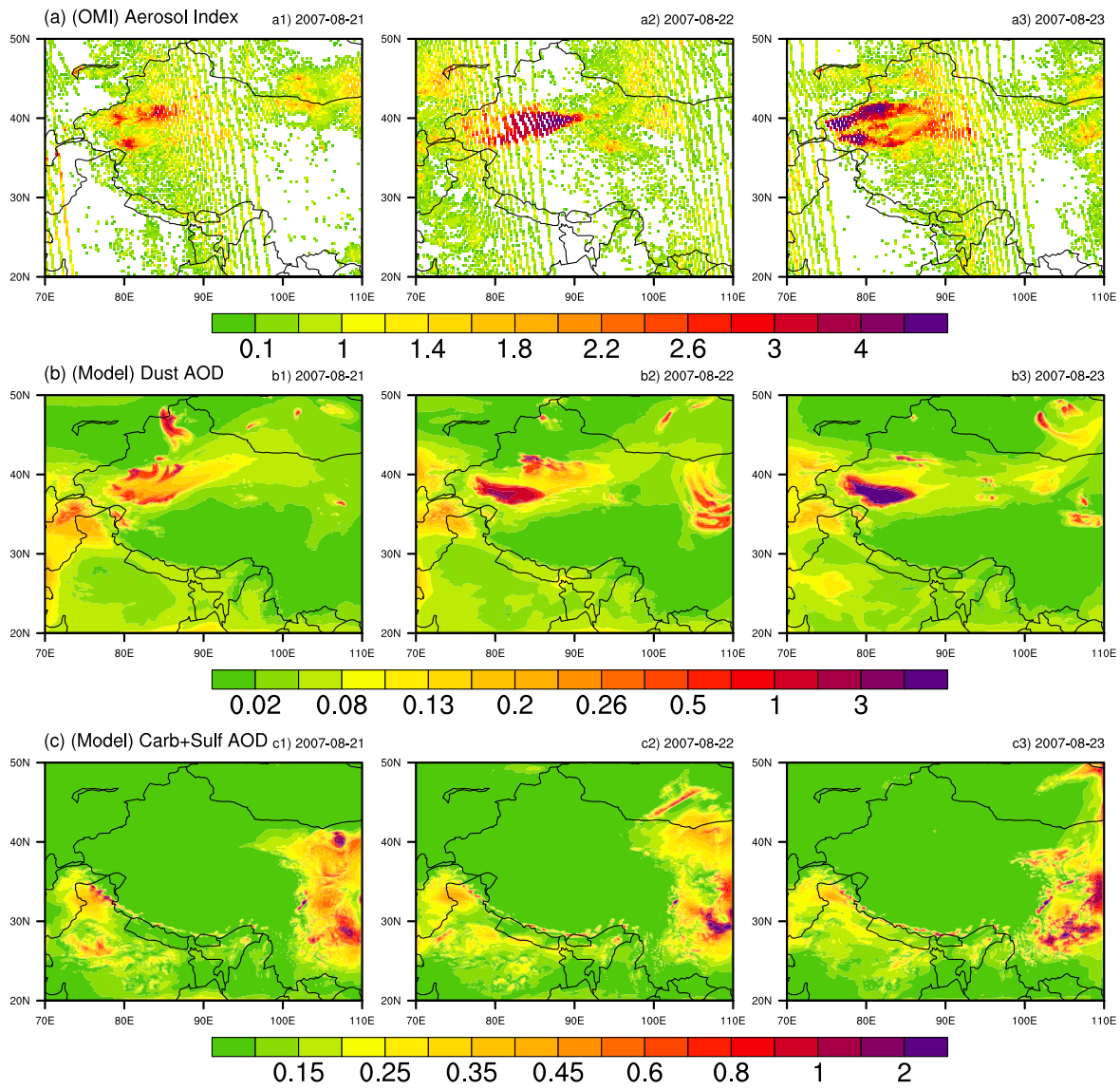

Figure 3. Daily mean distribution of the (a) AI retrieved from the OMI satellite data and simulated optical depth of (b) dust aerosols and (c) carbonaceous and sulfate aerosols from 21 to 23 August 2007.

(Fig. 2b and c). Figure 2a presents the AOD on 22 August 2007 over the TP. The large AOD values further verify the conclusion from the total attenuated backscatter and volume depolarization ratio. The dust plumes could extend up to approximately $7-8 \mathrm{~km}$ a.s.l. over the northern slope of the TP. The result also indicates that the dust plumes over the northern slope were much thicker than those over the southern slope of the TP.

Based on the dust event detected by the CALIPSO observations, the model simulation and relative analysis were performed in the following sections.

\subsection{Simulation and comparison with observations}

Considering the geographical features of the TP, we primarily investigated the simulations of dust, carbonaceous aerosols (organic and black carbon), and sulfate aerosols. The simulated optical depths of the dust, carbonaceous and sulfate aerosols from 21 August 00:00 UTC to 24 August 00:00 UTC are shown in Fig. $3 \mathrm{~b}$ and c. The OMI AI in the UV band, which can detect UV-absorbing aerosols, is shown in Fig. 3a. The AI from the OMI is gridded at $0.5^{\circ} \times 0.5^{\circ}$ from the satellite orbit files. Generally, the value of the AI ranges from -1.5 to 3.5 , in which negative and positive indicate the dominance of scattering (e.g., sulfate) and absorbing aerosols (e.g., black carbon and dust) (Christopher et al., 2008), respectively.

Although many invalid values exist in the OMI observational data, the AI suggests highly absorbing aerosols around the Taklimakan Desert, the southern slope and the area east of the TP, as shown in Fig. 3a. The highest AI value was greater than 3.5 on 23 August. Additionally, compared with the OMI observation, SPRINTARS observed similar AOD patterns over the northern slope (Fig. 3b), the southern slope and the east of the TP (Fig. 3c). The model simulation indicates that dust aerosols were primarily distributed over the northern slope of the TP, whereas anthropogenic aerosols, including carbonaceous and sulfate aerosols, were distributed over the southern slope and east of the TP. Combining the observations from the OMI and the SPRINTARS simulations, the absorbing aerosols over the north TP slope were dust, and those over the southern slope and east of the TP were carbonaceous materials.

Figure 4 shows the simulated distributions of the surface aerosol single scattering albedo (SSA) and Ångström expo- 

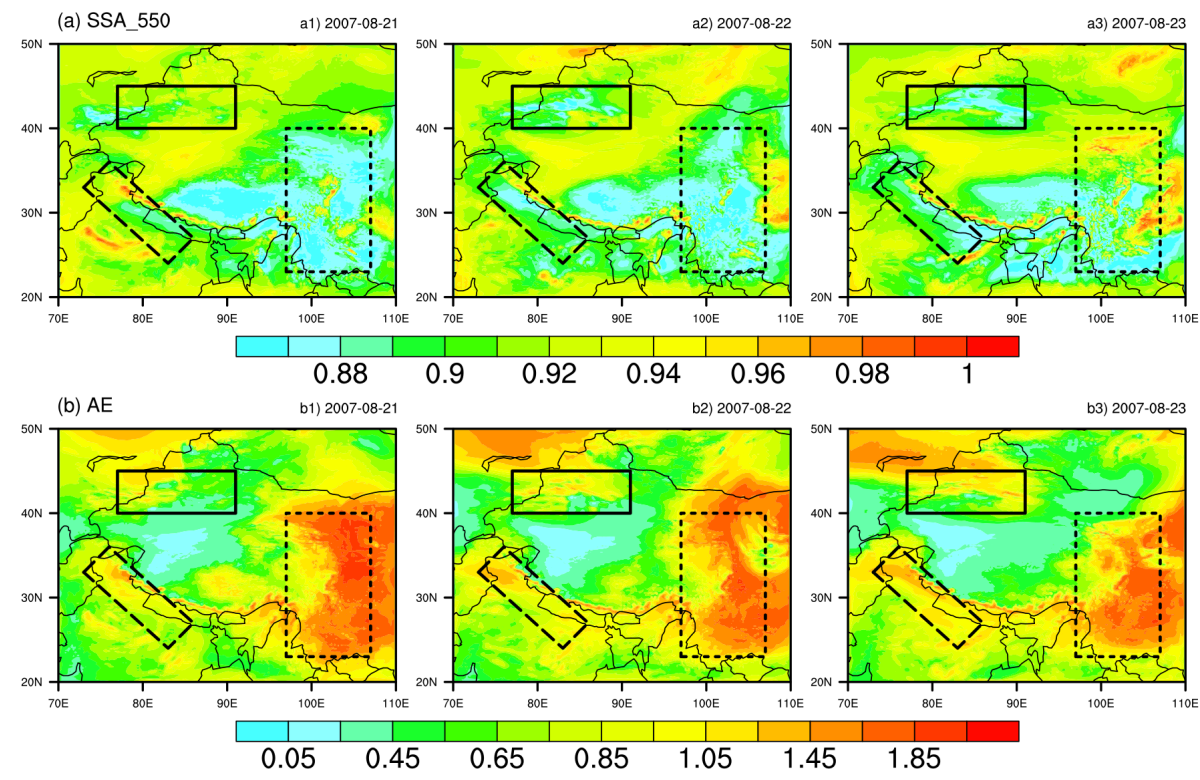

Figure 4. Simulated daily mean distributions of the (a) single scattering albedo and (b) Ångström exponent from 21 to 23 August 2007 . The black rectangles indicate three areas of interest.

nent (AE) for a mixed polydispersion of all aerosols in this study. The three black rectangles indicate the key areas where the values clearly change. In addition to the low SSA values over much of the snow cover, the SSA values around the Taklimakan Desert were as low as $0.85-0.91$ because of the strong absorption of direct solar radiation. From 21 to 23 August, the low SSA center clearly moved from the Taklimakan Desert to the northern slope and east part of the TP (shown in the solid boxes in Fig. 4). The decreasing SSA and AE imply increasing absorption and larger particles. As the dashed boxes indicate, over the southern slope of the TP, the SSA ranged from 0.88 to 0.91 and exhibited a decrease from 21 to 23 August. At the same time, to the east of the TP, the SSA values varied from approximately 0.85 to 0.98 while the AE values somewhat decreased from 21 to 23 August (dotted boxes). The simulations suggest that the eastward and southward migration of dust aerosols induced the increasing SSA over the northern slope and east of the TP, respectively; however, the carbonaceous aerosols contributed to the SSA variation over the southern slope of the TP. Additionally, over the east of the TP, the sulfate aerosols somewhat influenced the simulated SSA and AE values.

Although the satellite observations were compared with the horizontal distribution of aerosols over and around the $\mathrm{TP}$, in situ vertical observations are difficult to find due to the special geographical environment. Considering the limitation of the spatial and temporal coverage due to aerosol property retrievals over bright surfaces and beneath thin clouds, we compared the CALIPSO observations with the simulated vertical distribution along the orbit of CALIPSO/CALIOP at 20:18 UTC on 22 August 2007. Figure 5 presents the extinc- (a) CALIPSO extinction coefficient

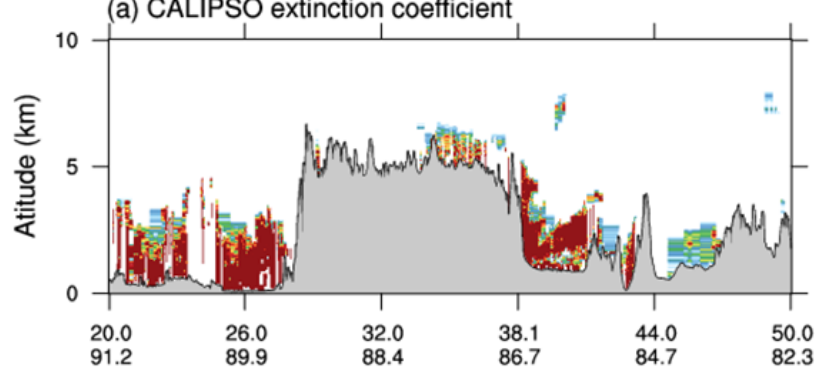

(b) SPRINTARS extinction coefficient

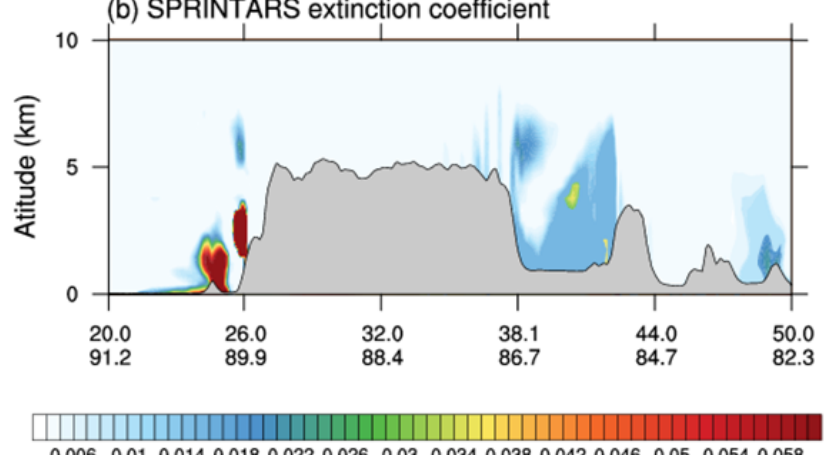

Figure 5. The vertical cross-section of the aerosol extinction coefficient (unit: $\mathrm{km}^{-1}$ ) from (a) CALIPSO and (b) the simulation by SPRINTARS on 22 August 2007. The gray shading indicates the topography.

tion coefficient of the CALIPSO retrieval and the model simulation along the orbit path (as shown in Fig. 1). Although a slight underestimation occurs in the SPRINTARS simulation, the comparison shows that the model can nearly rea- 
(a) (Model)Dust AOD_550

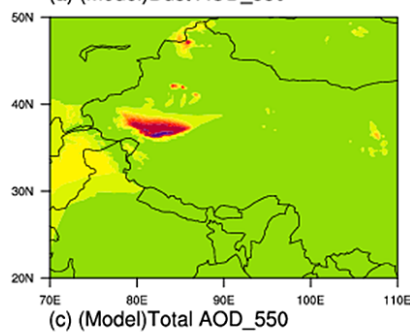

(b) (Model)Carbon+Sulfate AOD 550
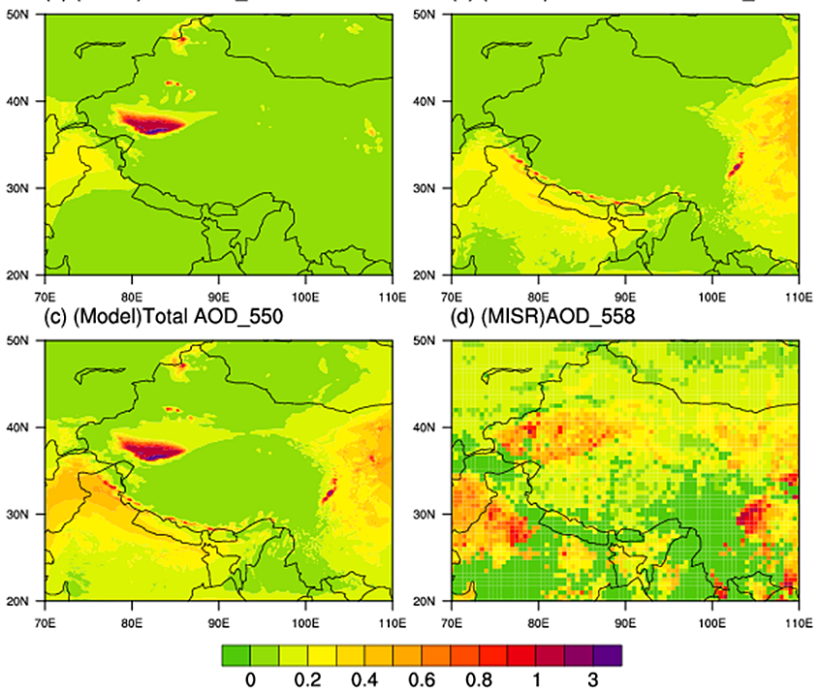

Figure 6. Monthly mean aerosol optical depths from the MISR and SPRINTARS simulations for August 2007.

sonably simulate the aerosol extinction profiles over most of the orbit path. Both the CALIPSO retrieval and SPRINTARS simulation show high aerosol loading around the Taklimakan Desert $\left(38-41^{\circ} \mathrm{N}\right.$ ) and the Tulufan Basin (approximately $43^{\circ} \mathrm{N}$ ). Based on the satellite observations and model simulations, aerosols over the Taklimakan Desert ascended over the TP, passing the northern slope, to 7-8 km a.s.l. (33$39^{\circ} \mathrm{N}$ ). Except for the underestimation of the extinction coefficient over the southern slope of the TP, the spatial patterns of the extinction coefficient between the observations and simulations agree well.

Considering the missing observations of MISR, we compared the simulated monthly mean aerosol optical properties with the satellite observations on August 2007 over the TP. Figure 6 compares the monthly mean AOD between the MISR observations (Fig. 6d), which are used in addition to the OMI, and the SPRINTARS simulations. Figure $6 a$ and $b$ describe the distributions of the AOD for dust and anthropogenic (carbonaceous and sulfate) aerosols, and the total AOD of four types of aerosols (dust, sulfate, sea salt, and carbonaceous aerosols) is represented in Fig. 6c. A comparison between Fig. $6 c$ and d shows that SPRINTARS can simulate the pattern and magnitude of the AOD extremely well. During August 2007, the monthly mean AOD reached over 1.5 around the Taklimakan Desert and the Sichuan Basin. The high optical depths around the Taklimakan Desert were primarily due to dust aerosols; however, the high values around the Sichuan Basin were primarily due to anthropogenic aerosols.

As suggested in Figs. 3 and 6, SPRINTARS can successfully simulate the distribution of dust and anthropogenic aerosols. The transport of the dust and anthro- pogenic aerosols to the TP is described in the following section.

\subsection{Transport of aerosols over the TP}

As indicated in the simulation of SPRINTARS over the TP area, dust particles are primarily distributed around deserts, such as the Taklimakan Desert, whereas carbonaceous and sulfate aerosols are primarily distributed in the northern India Peninsula and east of the TP. The transport of dust and anthropogenic aerosols over the TP from 21 to 23 August is further investigated.

Combining the distribution of the aerosol optical properties shown in Figs. 3 and 4, the high aerosol mass over the northern slope of the TP is attributed to dust, whereas the dominant aerosol type over the southern slope and east of the TP is anthropogenic. The dust aerosols over the northern slope of the TP predominately originate from the neighboring Taklimakan Desert. Near the southern slope of the TP, the anthropogenic aerosols in the east primarily originate from India, and the dust in the west primarily originates from the Great Indian Desert. Over the east of the TP, the dust particles primarily come from the Taklimakan Desert and from local dust sources, whereas anthropogenic aerosols originate from eastern China. The aerosols mobilized from the above sources are further transported to the TP during favorable meteorological conditions. Figure 7 presents the wind fields at the $850 \mathrm{hPa}$ level from ERA-Interim (a) and the fields at $z=20 \mathrm{~m}$ from SPRINTARS (b) during 21-23 August. The wind fields of SPRINTARS were averaged to the horizontal resolution of the ERA-Interim data $\left(1.0^{\circ} \times 1.0^{\circ}\right)$. In Fig. $7 \mathrm{~b}$, the arrows denote the $U$ and $V$ wind components in the horizontal direction, and the color indicates the vertical wind velocity, in which a positive value is a downdraft and a negative value is an updraft. Again, the comparison between the simulated fields and the observed fields proves the reliability of the SPRINTARS simulation. Comparing the vertical wind velocity over the southern slope, the updraft appears stronger over the northern slope of the TP.

The wind near the surface blows from Kazakhstan to the Tianshan and Altai Mountains, in which a northwesterly current continuously moves to the east, whereas another current turns into northeasterly wind toward the TP because of topographic blocking. Figure 7 suggests that with the northwesterly wind current, dust particles are transported to the east of the TP. At the same time, a large amount of dust is transported to the northern slope of the TP as northeasterly winds form. From 21 to 23 August, the northeasterly wind from the Tianshan and Altai Mountains was strongest on 22 August and weakened on 23 August. Furthermore, except for the northeasterly airflow toward the TP, an eastward airflow branched off of the northwesterly current, which apparently increased on 22 August. This airflow can transport dust that originated from the Taklimakan Desert to the eastern TP, as shown in Fig. 7. The movement of dust from the Taklimakan 


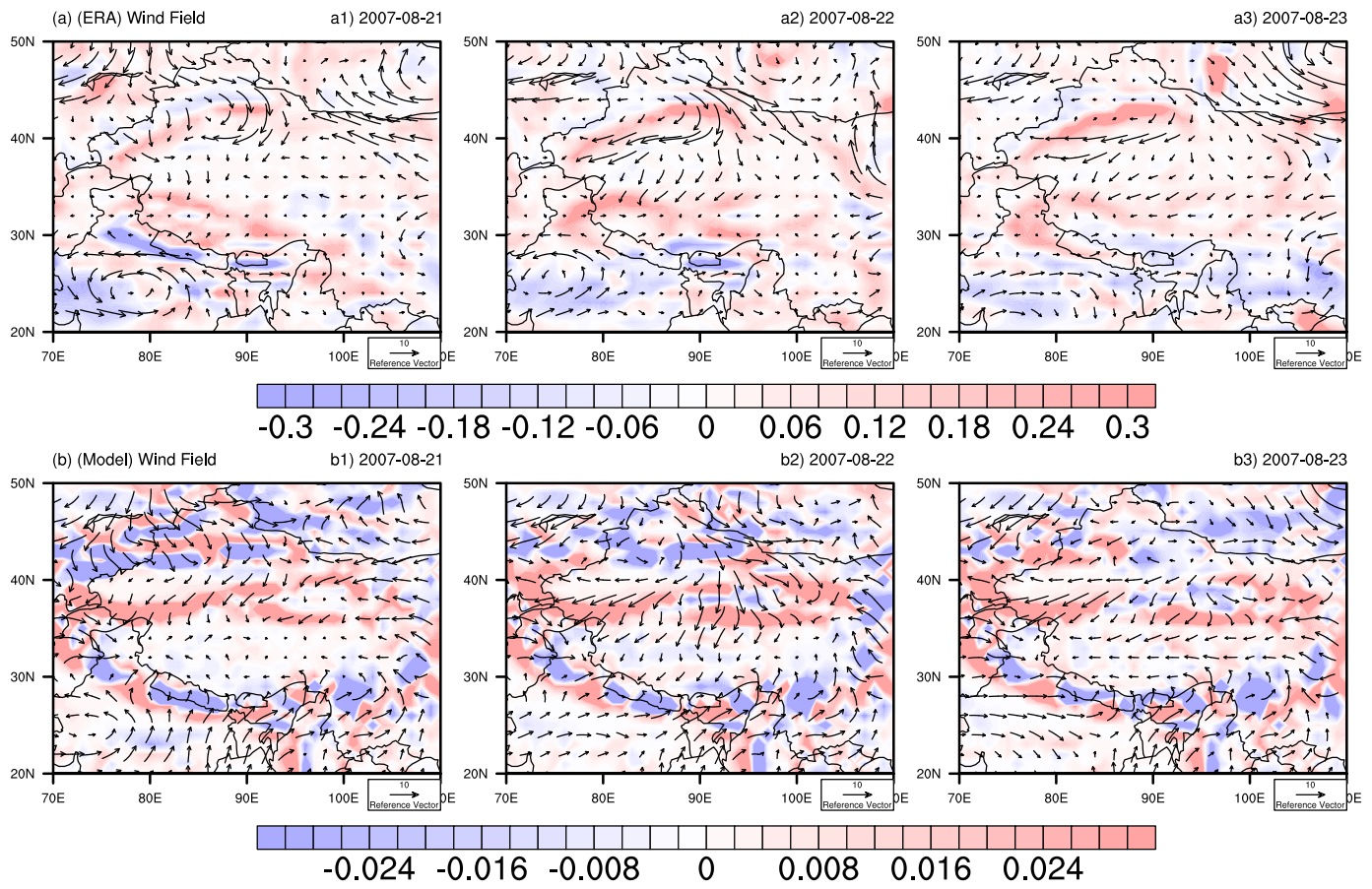

Figure 7. (a) Wind field from ERA-Interim at the $850 \mathrm{hPa}$ level (arrows for the $U$ and $V$ components of the horizontal wind, units: $\mathrm{m} \mathrm{s}^{-1}$; colors for the vertical wind velocity, the unit is $\mathrm{Pa} \mathrm{s}^{-1}$ and the values are negative for updrafts and positive for downdrafts) from 21 to 23 August 2007. (b) Same as (a) but for the simulated wind field at $20 \mathrm{~m}$ (units: $\mathrm{m} \mathrm{s}^{-1}$, the values of the vertical wind velocity are negative for downdrafts and positive for updrafts).

Desert to the east induces variations in the SSA and AE distributions, as shown in Fig. 4.

Additionally, Fig. 7 shows strong southwesterly wind from India. As shown in Fig. 7a1 and b1, the strong cyclone over the India Peninsula induced a northward transport of anthropogenic aerosols. According to Figs. 3 and 6, anthropogenic aerosols are transported to the southern TP with southwesterly winds from the India Peninsula. As the southwesterly wind weakens, the amount of transported anthropogenic particles declines, as shown in Fig. 3c3. Simultaneously, the anthropogenic aerosols from eastern China are transported to the eastern TP with easterly wind.

To determine the transport of aerosols in the horizontal and vertical directions, we analyzed the vertical variation in the dust mass concentration in the west-to-east and south-tonorth directions at $37^{\circ} \mathrm{N}$ and $78^{\circ} \mathrm{E}$, respectively, as shown in Fig. 8. The cross-sections cut across the center of high AOD area for dust aerosols, as shown in Fig. 3b, to explore the dust transport from 21 to 23 August 2007. As the easterly wind weakened and the northwesterly wind strengthened over the area from 22 to 23 August, dust aerosols were continuously transported eastward, as indicated by the increasing SSA in Fig. $4 \mathrm{a} 2$ and a3. As suggested in Fig. 8a1 and b1, on 21 August, the dust storm began to outbreak at approximately $78^{\circ} \mathrm{E}, 37^{\circ} \mathrm{N}$ and extended up to approximately $8 \mathrm{~km}$. Dust mobilization became more active and expansive the follow- ing day. With the development and transportation of the dust particles in the following 2 days, the particles were transported to higher and even upward to $9 \mathrm{~km}$ (Fig. $8 \mathrm{a} 3$ and b3). Simultaneously, the dust aerosols were substantially transported eastward during $70-80^{\circ} \mathrm{E}$ on 22 August, when the wind field favored eastward transport (Fig. 8a2). However, as shown in Fig. 8b2 and b3, most southward-transported dust particles were blocked and lifted up to the TP due to the orographic lifting. Based on Fig. 8b, updrafts existed near both the northern and southern slopes of the TP that lifted the dust to the plateau. The dust mass concentration was high in the west-east direction on 21 August and then strengthened over the following 2 days. The southward-transported particles accumulated over the northern slope of the TP, and peaked on 23. Figure 8 further proves that the dust over the northern slope of the TP originated from the deserts nearby, primarily the Taklimakan Desert. Combining Fig. $3 \mathrm{c}$ and the wind field in Fig. 7, we conclude that a large amount of anthropogenic aerosol was transported to the area east of the TP during the dust event and then weakened with the eastward transport of dust when the eastward airflow strengthened.

Corresponding to the transport of dust aerosols in the horizontal and vertical directions, Fig. 9 shows the distribution of dust mass column loading from 21 to 23 August. As suggested in Fig. 9, the dust loading is high over the northern and southern slopes of the TP. With the development and trans- 

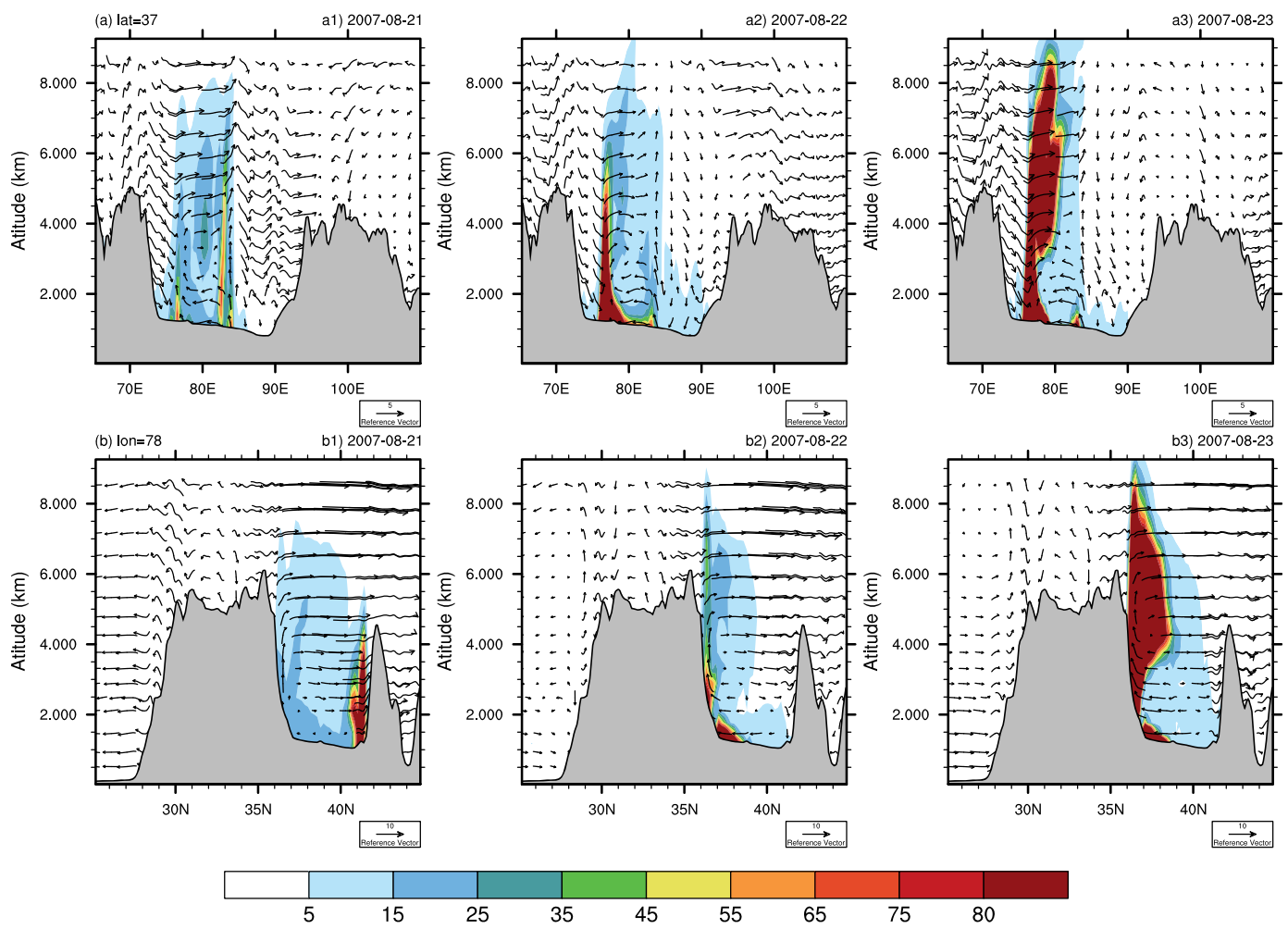

Figure 8. Cross-section of the (a) vertical-longitude and (b) vertical-latitude distributions of the simulated dust mass concentration (units: $\mu \mathrm{g} \mathrm{m}^{-3}$ ) and wind vectors (shown in arrows; the vertical velocity is multiplied by 10 and 30 for panels (a) and (b), respectively) from 21 to 23 August 2007. The gray shading indicates the topography.
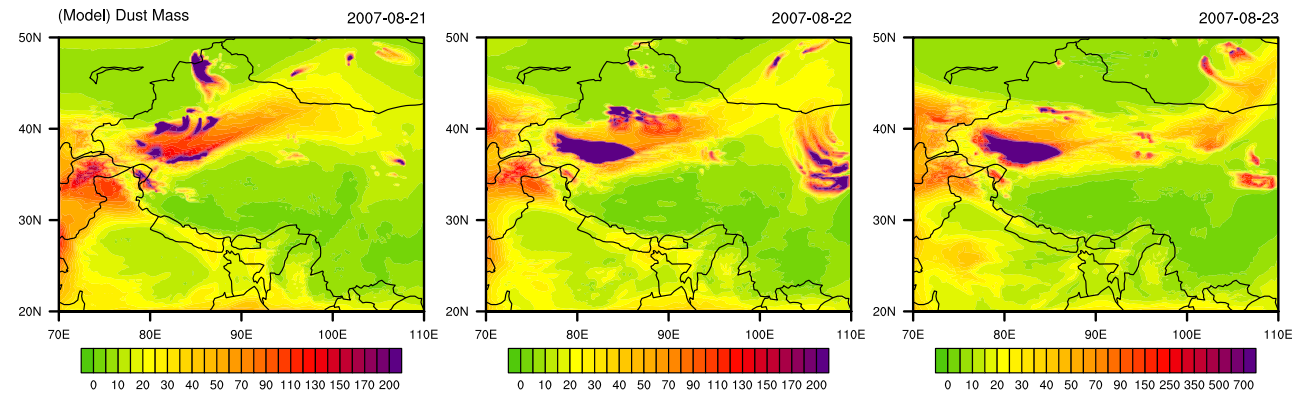

Figure 9. Distributions of the simulated dust mass column loading (units: $\mathrm{mg} \mathrm{m}^{-2}$ ) from 21 to 23 August 2007.

portation, dust mass concentration over the northern slope began to increase and extend southeastward on 21 August. On the following 2 days, 22-23 August, the dust event became severe and swept across the entire Tarim Basin. With the formation of the dust event on 21 August, the northeasterly wind over the northeastern TP was strong, and a large amount of carbonaceous aerosol was transported to eastern TP; this setup produced high AOD and low SSA values, as shown in Figs. 3c1 and 4a1, respectively.

\section{Conclusions}

In this study, we first evaluated the SPRINTARS model coupled with an NHM using CALIPSO, OMI and MISR observational data. Simultaneously, the summer dust and anthropogenic aerosols over the TP were evaluated, and the distributions over the TP were presented.

From the SPRINTARS simulations, dust aerosols contribute to the high AOD around the Taklimakan Desert, and the absorbing aerosols, mainly carbon, observed by the OMI satellite were distributed over the southern TP. SPRINTARS can simulate an AOD pattern similar to that observed by the OMI, with the exception of several high values over the 
east of the TP. Additionally, the model simulations suggest that anthropogenic aerosols, i.e., carbonaceous and sulfate aerosols, surround India and the Sichuan Basin. Compared with the vertical distribution of the aerosol extinction coefficient along the orbit of CALIPSO/CALIOP, SPRINTARS can reasonably simulate the aerosol extinction profiles over most of the orbit. SPRINTARS well simulated the pattern and magnitude of the monthly mean aerosol optical properties observed by the MISR on August 2007 over the TP. The aerosols were primarily anthropogenic particles in the east and southern slope of the TP but dust particles over the northern slope of the TP.

The vertical-longitude/latitude cross-sections of the SPRINTARS-simulated aerosol mass concentration show that the dust aerosols were emitted in the atmosphere at approximately $78^{\circ} \mathrm{E}, 37^{\circ} \mathrm{N}$ and extended up to approximately $8 \mathrm{~km}$ from the first day of the dust event. Then, the dust was transported upward to $9 \mathrm{~km}$; simultaneously, the dust aerosols were substantially transported east for the following day. During the southward transport, the dust particles were blocked and lifted up to the TP due to the orographic lifting of the plateau. As the dust event weakened, the transport weakened in both the vertical and horizontal directions. During the dust events, the model simulations showed that the Tibetan dust aerosols appeared at approximately 7$8 \mathrm{~km}$ a.s.1., and the plumes originated from the nearby Taklimakan Desert and accumulated over the northern slope of the TP during the summer.
The dust aerosols were transported eastward by strong northwesterly winds, whereas the dust was transported southward to the northern slope of the TP as the air current changed from northwesterly to northeasterly due to topographic blocking. Additionally, increasingly eastward airflows branched off from the northwesterly wind transport a portion of the dust aerosols to eastern China. Anthropogenic aerosols that originated from eastern China were transported to the east of the TP. Influenced by the Indian summer monsoon, anthropogenic aerosols were northwardly transported to the southern slope of the TP.

The impact of different aerosols on cloud properties and precipitation is an important issue. In the future, the interaction of dust and anthropogenic aerosols with the microphysical properties of clouds will be further investigated. 
Appendix A: Details of the MIROC-SPRINTARS data used for the initial and boundary conditions of the aerosol field of NHM-SPRINTARS

To create the initial and boundary conditions of the aerosol fields for NHM-SPRINTARS, we used the results of MIROC-SPRINTARS (Takemura et al., 2005; Goto et al., 2011). MIROC-SPRINTARS was based on the 6 hourly meteorological fields (temperature, winds, and water vapor) of NCAR/NCEP Reanalysis. The results of the calculation were used for the initial and boundary conditions in this study. The horizontal and vertical resolutions were set to $1.1^{\circ} \times 1.1^{\circ}$ and 20 layers, respectively. The emission inventories of anthropogenic black carbon (BC) and sulfur dioxide $\left(\mathrm{SO}_{2}\right)$ were generated by Streets et al. (2003) over Asia and by Takemura et al. (2005) over the remaining regions. The other inventories (biomass burning and volcanoes) were the same as those used in Takemura et al. (2005). In MIROC-SPRINTARS, the monthly mean oxidant distributions were prescribed from a global chemical transport model, MIROC-CHASER (Sudo et al., 2002), with a horizontal resolution of $2.8^{\circ} \times 2.8^{\circ}$. 
Acknowledgements. This research was jointly supported by the National Basic Research Program of China (2012CB955301), the National Natural Science Foundation of China (41475095 and 41275006), the Fundamental Research Funds for the Central Universities (lzujbky-2015-ct03, lzubjky-2014-109, and lzujbky2009-k03), and the China 111 project (B13045). Part of this research was supported by funds from MOEJ/S12\&GOSAT2, JST/CREST/TEEDDA, JAXA/EarthCARE\&GCOM-C. The CALIPSO data were obtained from the National Aeronautics and Space Administration (NASA) Langley Research Center Atmospheric Sciences Data Center. The ERA-Interim data were provided by the European Centre for Medium Range Weather Forecasts (http://apps.ecmwf.int/datasets/). The OMI and MISR data were provided by NASA (ftp://aurapar2u.ecs. nasa.gov/data/s4pa/Aura_OMI_Level2/OMAERO.003/ and https://eosweb.larc.nasa.gov/project/misr/mil3dae_table). The authors are extremely grateful to Takemura of Kyushu University and Goto of the National Institute for Environmental Research on Japan for developing and maintaining SPRINTARS. The authors are also thankful to Kajino of Meteorological Research Institute for his supplying code of advection scheme.

Edited by: T. Takamura

\section{References}

Breider, T. J., Mickley, L. J., Jacob, D. J., Wang, Q., Fisher, J. A., Chang, R. Y. W., and Alexander, B.: Annual distributions and sources of Arctic aerosol components, aerosol optical depth, and aerosol absorption, J. Geophys. Res.-Atmos., 119, 4107-4124, doi:10.1002/2013JD020996, 2014.

Chen, S., Huang, J., Zhao, C., Qian, Y., Leung, L. R., and Yang, B.: Modeling the transport and radiative forcing of taklimakan dust over the tibetan plateau: a case study in the summer of 2006 , J. Geophys. Res.-Atmos., 118, 797-812, doi:10.1002/jgrd.50122, 2013.

Chen, Y., Mao, X., Huang, J., Zhang, H., Tang, Q., Pan, H., and Wang, C.: Vertical distribution characteristics of aerosol during a long-distance transport of heavy dust pollution, China Environ. Sci., 29, 449-454, 2009.

Christopher, S. A., Gupta, P., Haywood, J., and Greed, G.: Aerosol optical thicknesses over North Africa: 1. Development of a product for model validation using Ozone Monitoring Instrument, Multiangle Imaging Spectroradiometer, and Aerosol Robotic Network, J. Geophys. Res.-Atmos., 113, D00C04, doi:10.1029/2007JD009446, 2008.

d'Almeida, G. A., Koepke, P., and Shettle, E. P.: Atmospheric Aerosols: Global Climatology and Radiative Characteristics, A. Deepak, Hampton, Va, 1991.

DeMott, P. J., Sassen, K., Poellot, M. R., Baumgardner, D., Rogers, D. C., Brooks, S. D., Prenni, A. J., and Kreidenweis, S. M.: African dust aerosols as atmospheric ice nuclei, Geophys. Res. Lett., 30, 1732, doi:10.1029/2003GL017410, 2003.

Gong, S. L., Zhang, X. Y., Zhao, T. L., Zhang, X. B., Barrie, L. A., McKendry, I. G., and Zhao, C. S.: A Simulated climatology of Asian dust aerosol and its trans-Pacific transport. Part II: Inter- annual variability and climate connections, J. Climate, 19, 104122, doi:10.1175/JCLI3606.1, 2006.

Goto, D., Nakajima, T., Takemura, T., and Sudo, K.: A study of uncertainties in the sulfate distribution and its radiative forcing associated with sulfur chemistry in a global aerosol model, Atmos. Chem. Phys., 11, 10889-10910, doi:10.5194/acp-1110889-2011, 2011.

Goudie, A. S. and Middleton, N. J.: Saharan dust storms: nature and consequences, Earth-Sci. Rev., 56, 179-204, doi:10.1016/S00128252(01)00067-8, 2001.

Hansen, J., Sato, M., Ruedy, R., Lacis, A., and Oinas, V.: Global warming in the twenty-first century: an alternative scenario, P. Natl. Acad. Sci. USA, 97, 9875-9880, doi:10.1073/pnas.170278997, 2000.

Hsu, S. C., Tsai, F., Lin, F. J., Chen, W. N., Shiah, F. K., Huang, J. C., Chan, C. Y., Chen, C. C., Liu, T. H., Chen, H. Y., Tseng, C. M., Hung, G. W., Huang, C. H., Lin, S. H., and Huang, Y. T.: A super Asian dust storm over the East and South China Seas: disproportionate dust deposition, J. Geophys. Res.-Atmos., 118, 7169-7181, doi:10.1002/jgrd.50405, 2013.

Huang, J., Ge, J., and Weng, F.: Detection of Asia dust storms using multisensor satellite measurements, Remote Sens. Environ., 110, 186-191, 2007a.

Huang, J., Minnis, P., Yi, Y., Tang, Q., Wang, X., Hu, Y., Liu, Z., Ayers, K., Trepte, C., and Winker, D.: Summer dust aerosols detected from CALIPSO over the Tibetan Plateau, Geophys. Res. Lett., 34, L18805, doi:10.1029/2007g1029938, $2007 \mathrm{~b}$.

Huang, J., Minnis, P., Yan, H., Yi, Y., Chen, B., Zhang, L., and Ayers, J. K.: Dust aerosol effect on semi-arid climate over Northwest China detected from A-Train satellite measurements, Atmos. Chem. Phys., 10, 6863-6872, doi:10.5194/acp-10-68632010, 2010.

Huang, J., Fu, Q., Zhang, W., Wang, X., Zhang, R., Ye, H., and Warren, S.: Dust and black carbon in seasonal snow across northern China, B. Am. Meteorol. Soc., 92, 175-181, doi:10.1175/2010BAMS3064.1, 2011.

Jacobson, M. Z.: Strong radiative heating due to the mixing state of black carbon in atmospheric aerosols, Nature, 409, 695-697, doi:10.1038/35055518, 2001.

Jing Su, Jianping Huang, Qiang Fu, Minnis, P., Jinming Ge, and Jianrong Bi: Estimation of Asian dust aerosol effect on cloud radiation forcing using Fu-Liou radiative model and CERES measurements, Atmos. Chem. Phys., 8, 2763-2771, doi:10.5194/acp8-2763-2008, 2008.

Kahn, R. A., Gaitley, B. J., Martonchik, J. V., Diner, D. J., and Crean, K. A.: Multiangle Imaging Spectroradiometer (MISR) global aerosol optical depth validation based on 2 years of coincident Aerosol Robotic Network (AERONET) observations, J. Geophys. Res.-Atmos., 110, D10S04, doi:10.1029/2004jd004706, 2005.

Kajino, M., Inomata, Y., Sato, K., Ueda, H., Han, Z., An, J., Katata, G., Deushi, M., Maki, T., Oshima, N., Kurokawa, J., Ohara, T., Takami, A., and Hatakeyama, S.: Development of the RAQM2 aerosol chemical transport model and predictions of the Northeast Asian aerosol mass, size, chemistry, and mixing type, Atmos. Chem. Phys., 12, 11833-11856, doi:10.5194/acp12-11833-2012, 2012.

Kaufman, Y. J., Tanré, D., Dobocik, O., Karnieli, A., and Remer, L. A.: Absorption of sunlight by dust as inferred from satellite 
and groundbased remote sensing, Geophys. Res. Lett., 28, 14791482, 2001.

Lamarque, J.-F., Bond, T. C., Eyring, V., Granier, C., Heil, A., Klimont, Z., Lee, D., Liousse, C., Mieville, A., Owen, B., Schultz, M. G., Shindell, D., Smith, S. J., Stehfest, E., Van Aardenne, J., Cooper, O. R., Kainuma, M., Mahowald, N., McConnell, J. R., Naik, V., Riahi, K., and van Vuuren, D. P.: Historical (1850-2000) gridded anthropogenic and biomass burning emissions of reactive gases and aerosols: methodology and application, Atmos. Chem. Phys., 10, 7017-7039, doi:10.5194/acp10-7017-2010, 2010.

Lau, K. M. and Kim, K. M.: Observational relationships between aerosol and Asian monsoon rainfall, and circulation, Geophys. Res. Lett., 33, L21814, doi:10.1029/2006g1027546, 2006.

Lau, K. M., Kim, M. K., and Kim, K. M.: Asian summer monsoon anomalies induced by aerosol direct forcing: the role of the Tibetan Plateau, Clim. Dynam., 26, 855-864, doi:10.1007/s00382006-0114-z, 2006.

Li, H., Zheng, W., and Gong, Q.: An analysis on detection of a sand-dust weather over Taklimakan Desert based on polarization micro-pulse lidar, Desert Oasis Meteorol., 7, 1-5, 2013.

Liu, Y., Huang, J., Shi, G., Takamura, T., Khatri, P., Bi, J., Shi, J., Wang, T., Wang, X., and Zhang, B.: Aerosol optical properties and radiative effect determined from sky-radiometer over Loess Plateau of Northwest China, Atmos. Chem. Phys., 11, 1145511463, doi:10.5194/acp-11-11455-2011, 2011.

Liu, Y., Shi, G., and Xie, Y.: Impact of dust aerosol on glacial-interglacial climate, Adv. Atmos. Sci., 30, 1725-1731, doi:10.1007/s00376-013-2289-7, 2013.

Liu, Y., Jia, R., Dai, T., and Shi, G.: A review of aerosol optical properties and radiative effects, J. Meteor. Res., 28, 1003-1028, doi:10.1007/s13351-014-4045-z, 2014.

Liu, Z., Liu, D., Huang, J., Vaughan, M., Uno, I., Sugimoto, N., Kittaka, C., Trepte, C., Wang, Z., Hostetler, C., and Winker, D.: Airborne dust distributions over the Tibetan Plateau and surrounding areas derived from the first year of CALIPSO lidar observations, Atmos. Chem. Phys., 8, 5045-5060, doi:10.5194/acp-85045-2008, 2008.

Martonchik, J. V.: Comparison of MISR and AERONET aerosol optical depths over desert sites, Geophys. Res. Lett., 31, L16102, doi:10.1029/2004g1019807, 2004.

Miller, R. L. and Tegen, I.: Climate response to soil dust aerosols, J. Climate, 11, 3247-3267, doi:10.1175/15200442(1998)011<3247:CRTSDA>2.0.CO;2, 1998.

Müller, D., Franke, K., Ansmann, A., Althausen, D., and Wagner, F.: Indo-Asian pollution during INDOEX: microphysical particle properties and single-scattering albedo inferred from multiwavelength lidar observations, J. Geophys. Res.-Atmos., 108, 4600, doi:10.1029/2003jd003538, 2003.

Nakajima, T., Sekiguchi, M., Takemura, T., Uno, I., Higurashi, A., Kim, D., Sohn, B. J., Oh, S. N., Nakajima, T. Y., Ohta, S., Okada, I., Takamura, T., and Kawamoto, K.: Significance of direct and indirect radiative forcings of aerosols in the East China Sea region, J. Geophys. Res.-Atmos., 108, 8658, doi:10.1029/2002JD003261, 2003.

Nakanishi, M. and Niino, H.: An improved Mellor-Yamada level-3 model: its numerical stability and application to a regional prediction of advection fog, Bound.-Lay. Meteorol., 119, 397-407, 2006.
Numaguti, A., Takahashi, M., Nakajima, T., and Sumi, A.: Description of CCSR/NIES atmospheric general circulation model. Study on the climate system and mass transport by a climate model, CGER's Supercomputer Monograph Report, 3, 1-48, Center for Global Environmental Research, National Institute for Environmental Studies, Tsukuba, Japan, 1997.

Onogi, K., Tsutsui, J., Koide, H., Sakamoto, M., Kobayashi, S., Hatsushika, H., Matsumoto, T., Kadokura, S., Wada, K. Kato, K., Oyama, R., Ose, T., Mannoji, N., and Taira, R.: The JRA-25 reanalysis, J. Meteorol. Soc. Jpn., 85, 369-432, doi:10.2151/jmsj.85.369, 2007.

Saito, K., Fujita, T., Yamada, Y., Ishida, J., Kumagai, Y., Anranami, K., Ohmori, S., Nagasawa, R., and Kumagai, S.: The Operational JMA Nonhydrostatic Mesoscale model, Mon. Weather Rev., 134, 1266-1298, doi:10.1175/mwr3120.1, 2006.

Shen, L., Sheng, L., and Chen, J.: Preliminary analysis of the spatial distribution of the dust aerosol in a heavy dust storm, J. Desert Res., 30, 1483-1490, 2010.

Sokolik, I. N. and Toon, O. B.: Direct radiative forcing by anthropogenic airborne mineral aerosols, Nature, 381, 681-683, doi:10.1038/381681a0, 1996.

Streets, D. G., Bond, T. C., Carmichael, G. R., Fernandes, S. D., Fu, Q., He, D., Klimont, Z., Nelson, S. M., Tsai, N. Y., Wang, M. Q., Woo, J.-H., and Yarber, K. F.: An inventory of gaseous and primary aerosol emissions in Asia in the year 2000, J. Geophys. Res.-Atmos., 108, 8809, doi:10.1029/2002JD003093, 2003.

Sudo, K., Takahashi, M., Kurokawa, J.-I., and Akimoto, H.: CHASER: a global chemical model of the troposphere 1 . Model description, J. Geophys. Res.-Atmos., 107, 4339, doi:10.1029/2001JD001113, 2002.

Takemura, T., Okamoto, H., Maruyama, Y., Numaguti, A., Higurashi, A., and Nakajima, T.: Global three-dimensional simulation of aerosol optical thickness distribution of various origins, J. Geophys. Res.-Atmos., 105, 17853-17873, doi:10.1029/2000jd900265, 2000.

Takemura, T., Uno, I., Nakajima, T., Higurashi, A., and Sano, I.: Modeling study of long-range transport of Asian dust and anthropogenic aerosols from East Asia, Geophys. Res. Lett., 29, 2158, doi:10.1029/2002GL016251, 2002.

Takemura, T., Nozawa, T., Emori, S., Nakajima, T. Y., and Nakajima, T.: Simulation of climate response to aerosol direct and indirect effects with aerosol transport-radiation model, J. Geophys. Res.-Atmos., 110, D02202, doi:10.1029/2004JD005029, 2005.

Tegen, I.: Modeling the mineral dust aerosol cycle in the climate system, Quaternary Sci. Rev., 22, 1821-1834, doi:10.1016/s0277-3791(03)00163-x, 2003.

Thulasiraman, S., O’Neill, N. T., Royer, A., Holben, B. N., Westphal, D. L., and McArthur, L. J. B.: Sunphotometric observations of the 2001 Asian dust storm over Canada and the U.S., Geophys. Res. Lett., 29, 96-1-96-4, doi:10.1029/2001GL014188, 2002.

Uno, I., Amano, H., Emori, S., Kinoshita, K., Matsui, I., and Sugimoto, N.: Trans-Pacific yellow sand transport observed in April 1998: a numerical simulation, J. Geophys. Res.-Atmos., 106, 18331-18344, doi:10.1029/2000JD900748, 2001.

Vaughan, M. A., Young, S. A., Winker, D. M., Powell, K. A., Omar, A. H., Liu, Z., Hu, Y., and Hostetler, C. A.: Fully automated analysis of space-based lidar data: an overview of the CALIPSO retrieval algorithms and data products, Laser Radar Tech. Atmos. Sens., 5575, 16-30, doi:10.1117/12.572024, 2004. 
Walcek, C. J. and Aleksic, N. M.: A simple but accurate mass conservative, peak-preserving, mixing ratio bounded advection algorithm with fortran code, Atmos. Environ., 32, 3863-3880, doi:10.1016/S1352-2310(98)00099-5, 1998.

Winker, D., Vaughan, M., and Hunt, B.: The CALIPSO mission and initial results from CALIOP, Proc. SPIE, 6409, 604902, doi:10.1117/12.698003, 2006.

Wu, G., Liu, Y., Zhang, Q., Duan, A., Wang, T., Wan, R., Liu, X., Li, W., Wang, Z., and Liang, X.: The influence of mechanical and thermal forcing by the Tibetan Plateau on Asianl Climate, J. Hydrometeorol., 8, 770-789, doi:10.1175/jhm609.1, 2007.
Yamada, Y.: Cloud microphysics, in: The JMA Nonhydrostatic Model, Annu. Rep., Jpn. Meteorol, Agency, 49, 52-76, 2003 (in Japanese).

Zhang, X. Y., Arimoto, R., Cao, J. J., An, Z. S., and Wang, D.: Atmospheric dust aerosol over the Tibetan Plateau, J. Geophys. Res.-Atmos., 106, 18471-18476, doi:10.1029/2000jd900672, 2001.

Zhao, Y., Jiang, Y., Zhang, X., and Lu, X.: Research on the depolarization ratio characteristic of the aerosol in the atmosphere with the CALIPSO satellite data, Acta Optica Sinaca, 29, 2943-2951, 2009. 